OPEN ACCESS

Edited and reviewed by: Angel Borja,

Technological Center Expert in Marine and Food Innovation (AZTI), Spain

*Correspondence: Toyonobu Fujii toyonobu.fujii.a8@tohoku.ac.jp

Specialty section: This article was submitted to Marine Ecosystem Ecology,

a section of the journal

Frontiers in Marine Science

Received: 26 April 2020 Accepted: 04 May 2020 Published: 29 May 2020

Citation:

Fujii T, Pondella DJ II, Todd VLG and Guerin A (2020) Editorial: Seafloor Heterogeneity: Artificial Structures and

Marine Ecosystem Dynamics.

Front. Mar. Sci. 7:378.

doi: 10.3389/fmars.2020.00378

\section{Editorial: Seafloor Heterogeneity: Artificial Structures and Marine Ecosystem Dynamics}

\author{
Toyonobu Fujii ${ }^{1 *}$, Daniel J. Pondella $I^{2}$, Victoria L. G. Todd ${ }^{3}$ and Andrew Guerin ${ }^{4}$ \\ ${ }^{1}$ Tohoku Ecosystem-Associated Marine Sciences, Graduate School of Agricultural Science, Tohoku University, Sendai, \\ Japan, ${ }^{2}$ Vantuna Research Group, Department of Biology, Occidental College, Los Angeles, CA, United States, ${ }^{3}$ Ocean \\ Science Consulting Ltd., Dunbar, United Kingdom, ${ }^{4}$ School of Natural and Environmental Sciences, Newcastle University, \\ Newcastle upon Tyne, United Kingdom
}

Keywords: artificial reefs, offshore oil and gas platforms, coastal infrastructure, aquaculture facilities, anthropogenic influences, ecological restoration, marine conservation, rigs-to-reef

\section{Editorial on the Research Topic}

\section{Seafloor Heterogeneity: Artificial Structures and Marine Ecosystem Dynamics}

Some of the most productives and biodiverse communities occur on "reefs" (Birkeland, 2015). Many species benefit from physical presence of habitat-forming reefs which provide complex three-dimensional hard substrates and a greater number of ecological niches (Loke et al., 2015). Although reefs are often exemplified by "corals," they also include other seafloor features such as biogenic substrates, natural bedrock, and man-made sub-sea structures (Steimle and Zetlin, 2000). Installation of sub-sea infrastructure is often considered to have negative impacts on surrounding marine ecosystems (Halpern et al., 2008; Benn et al., 2010; Bullieri and Chapman, 2010), although some studies show that such structures can also have beneficial effects by acting as "artificial reefs" (Gass and Roberts, 2006; Claisse et al., 2014).

Marine ecosystems are changing at alarming rates as a result of increasing anthropogenic influences (Halpern et al., 2008; McCauley et al., 2015; Duarte et al., 2020), and artificial structures are becoming ubiquitous. The sphere of influence, and effects of these artificial habitats on marine ecosystem dynamics, are poorly understood. This Research Topic assembles 11 articles investigating relationships between marine ecosystem dynamics and various types of anthropogenic structures globally. Here we present an overview of these contributions and highlight emerging views and future directions in this field.

\section{ARTIFICIAL REEFS FOR ECOLOGICAL ENHANCEMENT}

Callaway studied fauna inhabiting interstitial spaces within artificial reef units, built from rock or bivalve shell material, on an intertidal sand flat in Swansea Bay, UK. The reef units hosted greater biodiversity than nearby sediment, and the volume of interstitial space influenced species richness and community composition. Lohrer et al. manipulated artificial patches across experimental sites by inserting pinnid bivalve mimics into the seabed to observe the response of post-settlement stage snapper in Mahurangi Harbor, New Zealand. They showed that access to seafloor features and abundance of zooplankton are of primary importance to the snappers. 


\section{COASTAL FEATURES RELATING TO AQUACULTURE OPERATIONS AND RECREATIONAL ACTIVITIES}

Fujii et al. investigated dynamics of benthic macrofaunal communities in relation to changes in environmental factors, including the re-building of coastal aquaculture facilities in Onagawa Bay, Japan, after the 2011 Great East Japan Earthquake and tsunami. Coastal aquaculture facilities influenced the occurrence of benthic macrofaunal communities and facilitated recovery of seafloor biota at ecosystem scales. Macolino et al. investigated effects of boat moorings on sediment infauna in Sydney Harbor, Australia, and whether current impact assessment methodologies have sufficient sensitivity to detect such effects. Fine-scale effects of boating infrastructure were detected when considering distance to moorings; however, comparisons at large scales failed to detect ecological change, underlining the importance of sampling at multiple scales during impact assessments.

\section{EMERGING TECHNIQUES FOR MARINE HABITAT ASSESSMENT AND ECOSYSTEM RESTORATION}

Zellmer et al. used stacked-species distribution models (sSDMs) to identify optimal regions for restoration throughout the Southern California Bight, US. Using 21 ecologically important taxa and overlaying the s-SDMs with geospatial layers, they identified optimal areas for restoration. They also found that many man-made reefs in the area were placed in nonoptimal locales, highlighting the need to evaluate locations for future restoration activities. van Elden et al. reviewed the role that decommissioned oil and gas platforms play in their environment. Traditionally these structures are removed once decommissioned, but often this is no longer technically or economically feasible. These offshore installations are not directly comparable in many instances to natural ecosystems and, as such, they propose evaluating them as "novel ecosystems" facilitating appropriate assessment and decision-making processes.

\section{ARCHIVAL UNDERWATER IMAGERY FOR USE IN THE ASSESSMENT OF OFFSHORE OIL AND GAS INFRASTRUCTURE}

Thomson et al. used ROV-inspection footage to characterize the sessile invertebrates and fishes associated with an oil platform on the North West Shelf of Australia. Depth was a major driver of invertebrate assemblages; the highest densities of commercial species occurred around intermediate depths where small baitfish were abundant, suggesting that middepth platform sections had high habitat value. Rouse et al. examined northern North Sea inspection footage to assess abundance of organisms on and around offshore pipelines. They observed almost 60 taxa, including 12 that represented "features of conservation importance," demonstrating that even pipelines can have reef effects. Gates et al. reported results from visual inspection and physical sampling of an offshore structure decommissioned from an oil field in the North East Atlantic. They showed that structures enhanced the biomass of epifauna which, in turn, supported diverse associated macrofauna, providing a food source for motile invertebrates and fishes in an area where background hard substratum had been lost through the impacts of drilling. Todd et al. examined commercial ROV/diver imagery from global industrial partners and YouTube, and identified 17 species of marine megafauna, most of which displayed foraging and/or interaction with structures. They also reported the first confirmed visual sighting of a seal following a pipeline, and the deepest confirmed record of a sleeper shark, demonstrating the utility of online data sources to quantitatively elucidate relationships between offshore infrastructure and marine species. McLean et al. argue that, through cost-effective enhancements of ROV equipment and survey operations, offshore industry has the potential to contribute to our understanding of the impacts of artificial structures on the marine environment, and to collect invaluable data to support scientific investigation of changing marine ecosystems.

\section{EMERGING OPINIONS AND FUTURE DIRECTIONS}

This Research Topic provided a great opportunity to discuss our current understanding of: (1) the diversity and dynamics of human uses of the marine environment; (2) the responses of marine species, populations, communities and ecosystems to sub-sea artificial structures; and (3) the nature of their collective impacts on wider ecological processes. While Lohrer et al. did not identify the specific reason why early life-stage snappers had a positive affinity for structures, other studies reported that species used artificial structures as shelter or feeding ground (Callaway; Gates et al.; Thomson et al.; Todd et al.). Many authors also emphasized that the ecological significance of artificial structures must be considered within the context of the total footprint and the extent to which they contribute to biological connectivity and ecological processes operating at larger scales (Fujii et al.; Macolino et al.; Rouse et al.; Zellmer et al.). Furthermore, the authors who worked on offshore infrastructure were unanimous that access to global industry datasets can drive a better understanding of the changing ocean in areas impacted by anthropogenic activity. This, however, requires establishment of industry-academia partnerships to facilitate understanding of needs, priorities, and limitations of all parties (McLean et al.). With regard to issues surrounding decommissioning, van Elden et al. proposed a "novel ecosystem" approach to facilitate decision-making. Overall, this Research Topic provided a renewed insight into how distributional responses of different marine species are related to seafloor heterogeneity and shed new light on the broader role of marine artificial habitats. 


\section{AUTHOR CONTRIBUTIONS}

All authors listed have made a substantial, direct and intellectual contribution to the work, and approved it for publication.

\section{FUNDING}

TF was supported by grants-in-aid for scientific research by the Ministry of Education, Culture, Sports, Science, and Technology (MEXT/JSPS, Japan). DP was supported by

\section{REFERENCES}

Benn, A. R., Weaver, P. P., Billett, D. S. M., van den Hove, S., Murdock, A. P., Doneghan, G. B., et al. (2010). Human activities on the deep seafloor in the North East Atlantic: an assessment of spatial extent. PLoS ONE 5:e12730. doi: 10.1371/journal.pone.0012730

Birkeland, C. (2015). Coral Reefs in the Anthropocene. Berlin: Springer. doi: 10.1007/978-94-017-7249-5

Bullieri, F., and Chapman, M. G. (2010). The introduction of coastal infrastructure as a driver of change in marine environments. J. Appl. Ecol. 47, 26-35. doi: $10.1111 / j .1365-2664.2009 .01751 . x$

Claisse, J. T., Pondella, D. J., Love, M., Zahn, L. A., Williams, C. M., Williams, J. P., et al. (2014). Oil platforms off California are among the most productive marine fish habitats globally. Proc. Natl. Acad. Sci. U.S.A. 111, 15462-15467. doi: 10.1073/pnas.1411477111

Duarte, C. M., Agusti, S., Barbier, E., Britten, G. L., Castilla, J. C., Gattuso, J.-P., et al. (2020). Rebuilding marine life. Nature 580, 39-51. doi: 10.1038/s41586-020-2146-7

Gass, S. E., and Roberts, J. M. (2006). The occurrence of the cold-water coral Lophelia pertusa (Scleractinia) on oil and gas platforms in the North Sea: colony growth, recruitment and environmental controls on distribution. Mar. Pollut. Bull. 52, 549-559. doi: 10.1016/j.marpolbul.2005.10.002

Halpern, B. S., Walbridge, S., Selkoe, K. A., Kappel, C. V., Micheli, F., D’Agrosa, C., et al. (2008). A global map of human impact on marine ecosystems. Science 319:948. doi: 10.1126/science.1149345
California Ocean Protection Council, US National Science Foundation and US National Oceanic and Atmospheric Administration. VT was supported by Ocean Science Consulting Ltd.

\section{ACKNOWLEDGMENTS}

We thank all authors, reviewers, and the editorial staff of Frontiers in Marine Science for their support in producing this Research Topic.

Loke, L. H. L., Ladle, R. J., Bouma, T. J., and Todd, P. A. (2015). Creating complex habitats for restoration and reconciliation. Ecol. Eng. 77, 307-313. doi: 10.1016/j.ecoleng.2015.01.037

McCauley, D. J., Pinsky, M. L., Palumbi, S. R., Estes, J. A., Joyce, F. H., and Warner, R. R. (2015). Marine defaunation: animal loss in the global ocean. Science 347:1255641. doi: 10.1126/science. 1255641

Steimle, F. W., and Zetlin, C. (2000). Reef habitats in the Middle Atlantic Bight: abundance, distribution, associated biological communities, and fishery resource use. Mar. Fish. Rev. 62, 24-42.

Conflict of Interest: VT was employed by the company Ocean Science Consulting Ltd.

The remaining authors declare that the research was conducted in the absence of any commercial or financial relationships that could be construed as a potential conflict of interest.

Copyright (c) 2020 Fujii, Pondella, Todd and Guerin. This is an open-access article distributed under the terms of the Creative Commons Attribution License (CC BY). The use, distribution or reproduction in other forums is permitted, provided the original author(s) and the copyright owner(s) are credited and that the original publication in this journal is cited, in accordance with accepted academic practice. No use, distribution or reproduction is permitted which does not comply with these terms. 